\title{
STUDY OF THE MECHANICAL BEHAVIOR OF LIGHT MORTARS PRODUCED BY THERMAL TREATMENT, WITH COAL WASTE OF JERADA MINE (EASTERN MOROCCO) \\ R. ADDOU ${ }^{1}$, K. HANNAWI SALMO ${ }^{2}$, Z. ZENASNI ${ }^{3}$, W. P. AGBODJAN ${ }^{2}$, M. ZENASNI ${ }^{1}$
}

${ }^{1}$ Laboratory of Mechanics and Numerical Computing 'LM2N', National School of Applied Sciences, Oujda, Morocco.

${ }^{2}$ Laboratory of Civil Engineering and Mechanical Engineering 'LGCGM', INSA of Rennes, Rennes, France.

${ }^{3}$ Laboratory of Sciences and Professions of the Engineer, ENSAM, Moulay Ismail University, Meknes, Morocco.

\begin{abstract}
This paper investigates the mechanical properties of light mortars containing coal waste of Jerada mine, as a volume replacement for sand, with different percentages of substitution: $10 \%, 20 \%$ and $50 \%$.

The results revealed a decrease in the mechanical properties of composite mortars, including uniaxial compression and flexural strength as well as rigidity modulus. However, the heat treatment improves their ductility, and delays the propagation of cracks.

Thus, the developed material is interesting for use in construction, serving as a basis for manufacturing prefabricated blocks treated at $600^{\circ} \mathrm{C}$. These elements can be used for applications with large deformations, or with mechanical or acoustic vibrations.
\end{abstract}

Keywords : Light mortar - heat treatment compressive strength - bending - ductility - elastic modulus.

\section{Introduction}

Sterile coal waste of the Jerada mine (Eastern Morocco) has been the subject of several studies [1], [2] and [3] of upgrading in the building materials sector, which will make it possible to respond to the triple problematic altogether: looking for efficient and sustainable materials with local resources, reducing environmental impacts and energy efficiency.

The first step of this research work [4] focused on the mineralogical, chemical and thermal characterization of these mining wastes, then on their reactivity in cement mixture. As a result, we found that coal waste rock did not have a significant reactivity [5]. The activity index determined by mass substitution of the cement is lower than the value fixed by the ASTM C618 standard. Thus, the rest of this work was reoriented towards the possibility of using coal waste no longer as a substitute for cement but rather as granulate, as a volume replacement for the sand.

On the physical level, composite mortars obtained after heat treatment at $600{ }^{\circ} \mathrm{C}$ have showed a significant decrease in apparent density, which opens the possibility of their use as a lightweight construction material. Furthermore, additions and heat treatment resulted in a change in cementitious matrix microstructure, including increased porosity and void quantity, which resulted in increased gas permeability, decreased the propagation velocity of ultrasonic waves and a slight reduction in thermal conductivity compared to the reference mortar [4].

The purpose of this paper is to examine the mechanical properties of developed mortars, through studying their mechanical behavior, based on the compression test and the three-point bending test.

\section{Experimental procedure}

\subsection{Materials}

-Cement

For this study, we have used a Lafarge artificial portland cement (CEM I 52.5). Its relative density equals to 3.15, and its specific surface area measured by the BET method equals to $2.96 \mathrm{~m}^{2} / \mathrm{g}$.

- Sand

We used ordinary sand, with a continuous granulometry and its density equals to 2.65 .

\section{- Coal waste}

We used the waste in its raw state, keeping only the granular class $0 / 5$, to use it as a sand replacement. Its density equals to 2.66 .

\subsection{Specimen preparation}

The waste is conditioned in the granular class $0 / 5$ and introduced into the mortar as a partial volume substitution of the sand. Three volume percentages were retained $10 \%, 20 \%$ and $50 \%$. The different compositions are grouped together in Table 1:

Table 1: Composition of elaborate mortars

\begin{tabular}{lllll}
\hline Coal waste content & $\mathbf{0 \%}$ & $\mathbf{1 0 \%}$ & $\mathbf{2 0 \%}$ & $\mathbf{5 0 \%}$ \\
\hline $\begin{array}{l}\text { Water }\left(\mathbf{k g} / \mathbf{m}^{\mathbf{3}} \text { of }\right. \\
\text { concrete) }\end{array}$ & 256.5 & 256.5 & 256.5 & 256.5 \\
\hline $\begin{array}{l}\text { Cement }\left(\mathbf{k g} / \mathbf{m}^{\mathbf{3}} \text { of }\right. \\
\text { concrete) }\end{array}$ & 513 & 513 & 513 & 513 \\
\hline Sand $\left(\mathbf{k g} / \mathbf{m}^{\mathbf{3}}\right.$ of concrete) & 1539 & 1385 & 1231 & 769.5 \\
\hline $\begin{array}{l}\text { Coal waste }\left(\mathbf{k g} / \mathbf{m}^{\mathbf{3}} \text { of }\right. \\
\text { concrete) }\end{array}$ & 0 & 154.28 & 308.56 & 771.41 \\
\hline
\end{tabular}

\subsection{Tests and methods}

\subsubsection{Uni-axial compression test}

The machine used in our study is a hydraulic press INSTRON $200 \mathrm{KN}$ programmable and servocontrolled in displacement. The tests are carried out with a displacement speed of $0.25 \mathrm{~mm} / \mathrm{min}$. The press platens are lightly lubricated with a grease to reduce friction and reduce hooping. During the test, the specimen is loaded 
by the axial displacement of the cylinder. The displacement is measured using a sensor connected to the central acquisition. The force applied by the press is measured from the hydraulic pressure of the circuit by a force sensor, also connected to the acquisition unit. See

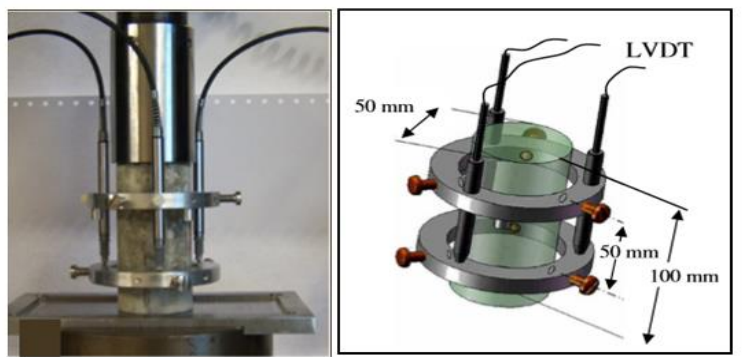

Figure 1.

Figure 1: Mounting diagram for axial displacement measurement under compressive load

For the uni-axial compression test, cylindrical specimens $(5 \mathrm{~cm} \times 10 \mathrm{~cm})$ were developed with varying contents of coal waste and half of them were preheated to $600^{\circ} \mathrm{C}$.

\subsubsection{Three-point bending test}

According to standard NF EN 196-1, the bending strength of a mortar is determined by three-point loading until rupture of $4 \times 4 \times 16 \mathrm{~cm}$ prismatic specimens. The bending stress is calculated by:

$$
\mathbf{f}=\mathbf{1 , 5} \times\left(\mathbf{F L} / \mathbf{b d}^{2}\right) \text { with : }
$$

$\checkmark$ f: bending strength [N/mm²]

$\checkmark$ b et $\mathrm{d}$ : width and thickness [mm]

$\checkmark$ F : maximum bending load [N]

$\checkmark$ L: distance between axes of the carrier rollers [mm].

The tests were carried out using a mechanical press of the Controls brand. See Figure 2.

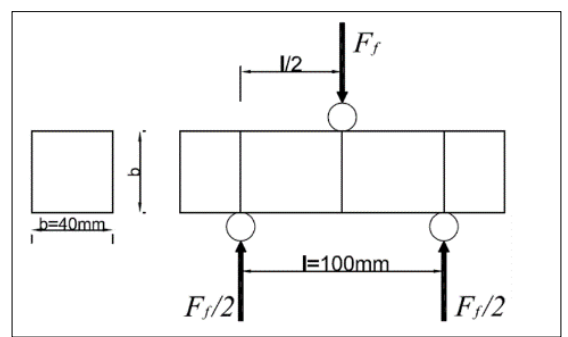

Figure 2 : Three-point bending test

\section{Results and discussion}

\subsection{Compressive strength}

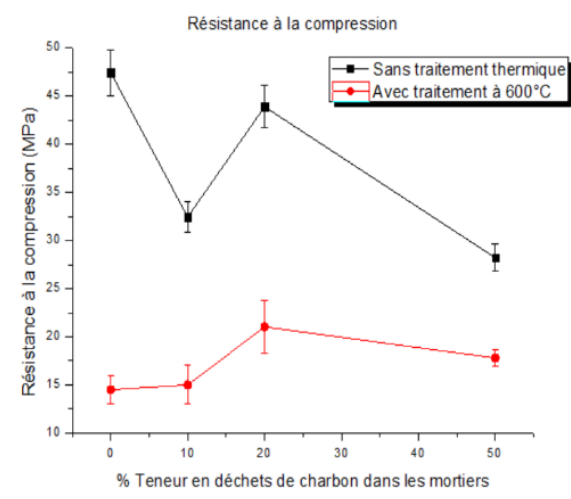

Figure 3: Evolution of the maximum compressive stress in composite mortars with waste content and heat treatment
From the curve in figure 3, we can note a reduction of the compressive strength caused by volume replacement of the sand by the sterile coal waste. This is primarily due to the high porosity of the mortars containing the coal waste (especially for high substitution rates); then to the imperfect adhesion of the grains of sterile with the cement matrix.

This is visible on the images recorded under a scanning electron microscope, respectively on the reference mortar and the 50\% mortar, where the adhesion is better between the cement paste and the normal sand than between the cement paste and the aggregates of coal waste. See Figure 4 (a) and (b).
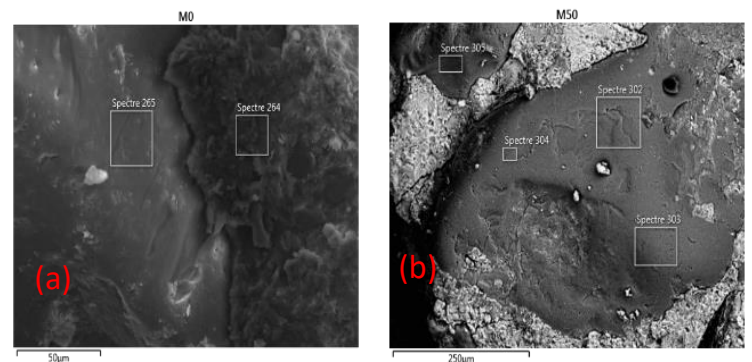

Figure 4 : SEM images, showing the type of contact between the aggregates and the cement matrix in the reference mortar (a) and $50 \%$ composite (b)

After treatment at $600^{\circ} \mathrm{C}$, the strengths obtained are significantly lower than those of untreated mortars are. Still all the composite mortars have superior resistance to the reference mortar. This may be a consequence of sintering occurring locally between the grains because of burning coal waste.

\subsection{Ductile behavior}

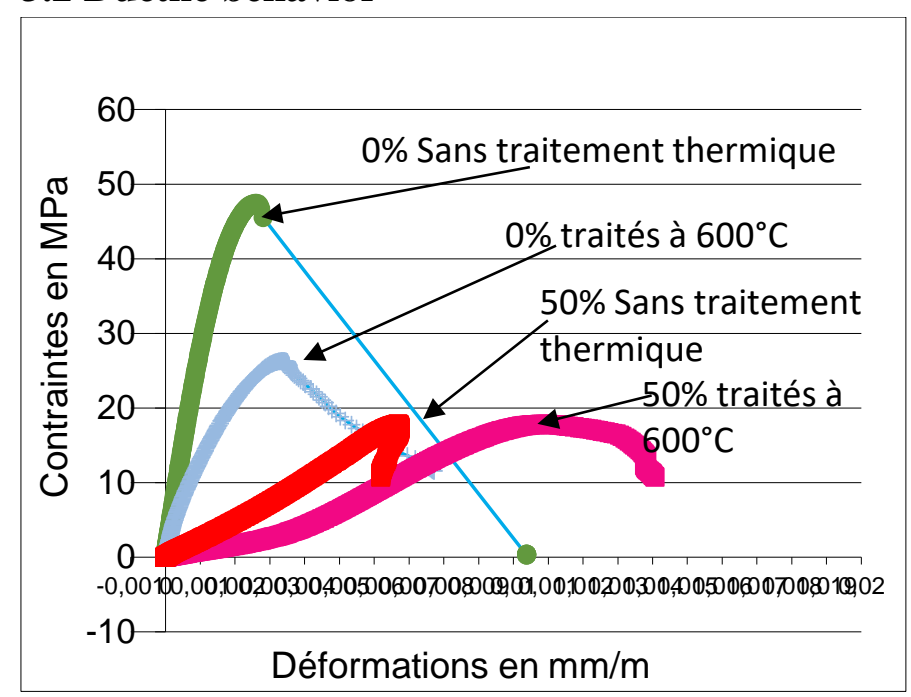

Figure 5: Stress-strain curves obtained by compression tests

In figure 5, we noticed that the heat treatment at $600^{\circ} \mathrm{C}$ of the reference mortars causes a reduction of the compressive strength, a decrease of the Young's modulus and an increase of the ductility. On mortars with a 50\% substitution, the heat treatment has little effect on the 
strength but it causes a decrease in rigidity and a very important increase in ductility. The ductility is also reflected in the facies of the test pieces after rupture. See Figures 6 and 7.
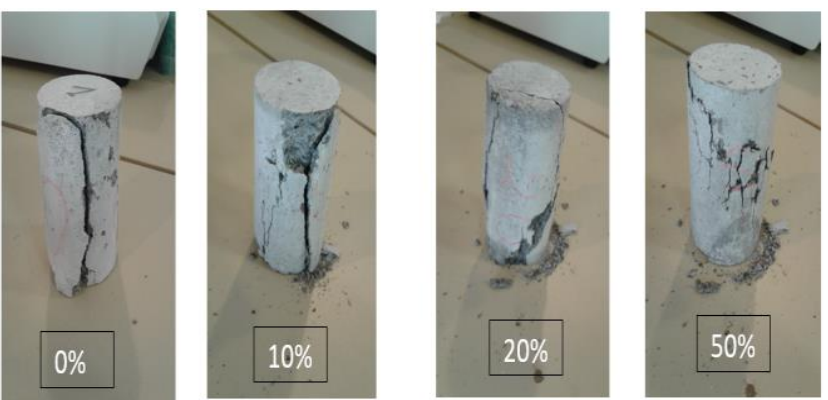

Figure 6: the appearance of the samples after rupture (specimens without heat treatment)
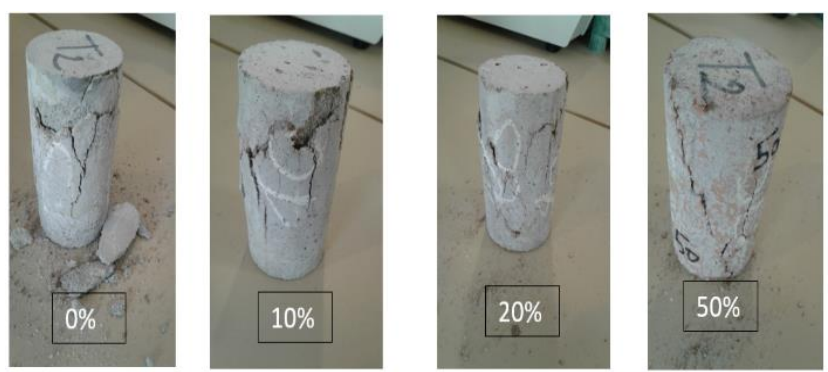

Figure 7: the appearance of the samples after rupture (specimens with heat treatment at $600^{\circ} \mathrm{C}$ )

Indeed, there is a delay in the opening of cracks and a reduction of the risk of sudden fragmentation of the test pieces.

\subsection{Three-point bending strength}

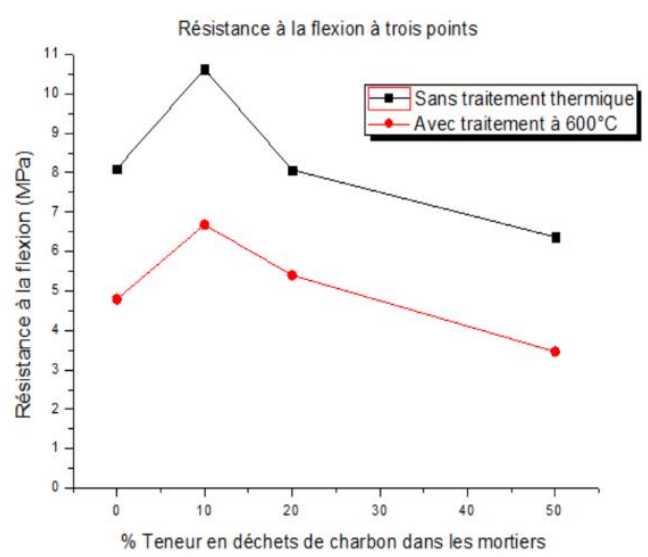

Figure 8: Evolution of three-point bending strength as a function of coal waste content and heat treatment.

We take note that the flexural strength increases for low rates of substitution (10\%) but decreases beyond this value. See Figure 8 . We also take note that, as with the compressive strength, the flexural strength decreases under the effect of the heat treatment at $600^{\circ} \mathrm{C}$.

\section{Conclusion}

The results show that the incorporation of coal waste into the mortars causes the decrease in compressive and flexural strength. Moreover, after heat treatment at $600^{\circ} \mathrm{C}$, all composites containing coal waste have a higher compressive strength than the reference mortar. In addition, under compressive loads, the heat treatment of the mortars at $600^{\circ} \mathrm{C}$ retards the abrupt propagation of cracks and moderates greatly the sudden failure observed for usual mortars. Thus, the elaborate mortars could be interesting for use in construction, serving as a basis for the manufacture of prefabricated blocks in the factory, and treated at $600^{\circ} \mathrm{C}$. These elements can be used in applications where it is necessary to limit the propagation of cracks generated by unavoidable deformations, or to damp mechanical or acoustic vibrations.

\section{References}

[1] Y. Taha et al, Coal mine wastes recycling for coal recovery and eco-friendly bricks production, Minerals Engineering Volume 107, (2017), 123-138

[2] D. Belkheiri, Étude de la valorisation de la gangue de charbon de JERADA dans l'élaboration d'un clinker Portland, Thèse, Université Mohammed V Rabat, 2016.

[3] Y. Darmane et al, Recycling the slagheap of an old coal mine (Morocco), Separation and Purification Technology Volume 68, (2009), 125-128.

[4] R. Addou, Elaboration et Caractérisation physicomécanique de mortiers de construction à base de déchets stériles de charbon de la mine de Jerada, Thèse, Université Mohamed $1^{\text {er }}$ Oujda, 2018.

[5] R. Addou et al, Characterization of Moroccan Coal Waste (Jerada Mine): Impact on Physical Properties of Mortars Made of Coal Waste, Journal of Materials and Environment Science Volume 10, (2017), 3473-3482. 